\title{
A Comparative Study on Healing Of Diabetic Foot Ulcers Using Total Contact Cast Vs Ambulatory Walking Cast Vs Modified MCR Sandals
}

\author{
${ }^{1}$ Dr.A.Sundarambal M.S., ${ }^{2}$ Prof. Dr.C.Rajasekaran M.S., ${ }^{3}$ Dr.B.Ramkumar \\ ${ }^{1}$ Assistant Professor, ${ }^{2}$ Professor and Head, ${ }^{3}$ Postgraduate, Dept. Of General Surgery, Govt. Mohan \\ Kumaramangalam Medical College, Salem, Tamilnadu.
}

\begin{abstract}
Objective:To determine the outcome of diabetic neuropathic ulcer treated using various off-loading device; Total contact cast vs Ambulatory Walking Cast vs modified MCR sandals in terms of percentage of ulcer healed and time taken to heal.

Study Design: RCT

Place and duration of study is Department of General Surgery, Government Mohan Kumaramangalam Medical College Hospital and Salem.

Methodology:The study includes diabetic patients with non-ischaemic neuropathic foot ulcers who were debrided off necrotic tissues and the device applied. The patients were reviewed at 2 to 3 weeks interval till wound healing. The device was considered failure when there was no reduction in ulcer size in 4 consecutive weeks or worsening to a higher grade. Main outcomes were time taken for the ulcer to heal and percentage of ulcer healed by various devices.

Results: There were 40 males and 20 females included in this study. The mean age was 45. All patients had diabetic mellitus. In the study conducted, the TCC group has a better healing rate and faster healing time than ambulatory walking cast and modified MCR chappels.
\end{abstract}

Keywords: Diabetic neuropathic ulcer, Total contact cast, Ambulatory walking cast, Modified MCR sandals.

\section{Introduction}

Diabetes is a common disease affecting about $7 \%$ of Indian adult population. Foot ulceration is common affecting about 15\%-25\% of diabetic patients during their lifetime. DFC are complex wounds attributed to various reasons such as neuropathic changes, vascular changes, defect in neutrophilic function and protein synthesis. Among these neuropathic changes are responsible for more than $60 \%$ of diabetic foot ulcers. Off-loading is an essential component in the management of diabetic neuropathic ulcers. The study aims to discuss various modalities of off-loading methods and their efficacy in healing neuropathic ulcers.

\section{Aim Of Study}

- To assess the efficacy of healing of diabetic plantar ulcers using various off-loading device - total contact cast versus ambulatory walking cast versus modified MCR chappels.

- To identify the most effective off-loading device in DFC

- To study the strength and limitations of off-loading devices used.

- To study the compliance of each technique

\section{Materials And Methods}

60 patients with Wegner's grade $1 \& 2$ ulcer foot with type 1 or 2 diabetes mellitus who attended general outpatient department of government Mohan Kumaramangalam medical college hospital were data source. Individuals who fulfilled the inclusion criteria were enrolled for the study and randomized into three groups of 20 each. Group A patients were chosen for total contact cast application,Group B patients for removable walking cast and Group C Patients for modified MCR chappels application. The outcome, following the procedure was recorded. All patients were treated as outpatient /inpatient by a team approachDiabetologist,General surgeon, Orthopaedician, Radiologist, Microbiologist,and Staff nurse. The ulcer size was measured in two dimensions length and breadth and recordings done on the initial day of treatment and the same procedure repeated at every subsequent visit-a week or two. Foot ulcers were documented by photographs. Footwear, off-loading devices and compliance were inspected at every visit and corrections made when required. Wound debridement and callus removal done. Vascular compromise was excluded through Doppler arterial study of affected limb. Neuropathy confirmed by $10 \mathrm{~g}$-semmes Weinstein monofilament test and vibration sense with $128 \mathrm{HZ}$ tuning fork. Glycaemic management throughout the study was taken over by the 
Physician.Inclusion criteria: Type $1 \& 2$ diabetes,Wegner's grade $1 \& 2$, both male and female. Exclusion criteria:Wegner's grade 3, 4,5, Wound swab positive, Peripheral arterial disease, Gangrene, Osteomyelitis of foot, Gross deformity of foot

Student t-test (paired t-test) was used as the statistical test to analyse the data obtained in this study.Outcomes were divided into primary \& secondary outcome.Primary outcome:ulcer healing rate, time Secondary outcome:reduction in ulcer size, complications, compliance.

\section{Results}

In the present study 60 patients were randomized into group A (TCC), group B (AWC), and group C (modified MCR chappels) of 20 patients each. Ulcer survey was made on 1, 4, 7,14,21, and 28 thereafter every week or two weeks until wounds healed. most of the patients studied in the age group 51-60 years (53.33\%),patients in age group 61-70 years were only 5 of them(8.3\%).there were 40 males and 20 females , there was not significant difference in healing of ulcers based on the age of patient. Most of the patients in this study had duration of diabetes over 5 years. The ulcers over the forefoot heals better than hind foot ulcers. In group A patients most of the ulcers less than $2 \mathrm{~cm}$ square heal by up to 60 days, ulcers more than $3 \mathrm{cms}$ square take more than 100 days to heal, in group B patients average time taken for ulcers to heal is $60-100$ days, in group $\mathrm{C}$ patients it takes more than 12 weeks to heal, some ulcers don't heal, remain same in size. Edema was reported in 5 cases with 3 patients in AWC and 2 cases in MCR group. The risk of infection increases with ulcer size more with the MCR group rather than AWC group.

Table 1 Distribution based on duration of diabetes.

\begin{tabular}{|l|l|l|}
\hline Duration of diabetes & Total noof patients & Percentage \\
\hline $0-5$ years & 1 & $1.67 \%$ \\
\hline $6-10$ years & 35 & $58.33 \%$ \\
\hline $11-15$ years & 23 & $38.33 \%$ \\
\hline $16-20$ years & 1 & $1.67 \%$ \\
\hline
\end{tabular}

Table 2 Healing rate by various off-loading techniques.

\begin{tabular}{|l|l|l|l|}
\hline & Total no of patients & No of healed subjects & Healing rate (\%) \\
\hline TCC & 20 & 19 & $95 \%$ \\
\hline RCW & 20 & 17 & $85 \%$ \\
\hline
\end{tabular}

Table 3 Ulcer healing based on duration of ulcer.

\begin{tabular}{|l|l|l|l|l|}
\hline & Distribution of ulcer & No of patients & No of patients healed & Percentage \\
\hline \multirow{3}{*}{ TCC } & Less than 5 months & 16 & 16 & $100 \%$ \\
\cline { 2 - 5 } & Greater than 5 months & 4 & 3 & $75 \%$ \\
\hline \multirow{3}{*}{ AWC } & Less than 5 months & 12 & 12 & $100 \%$ \\
\cline { 2 - 6 } & Greater than 5 months & 8 & 5 & $62.5 \%$ \\
\hline \multirow{3}{*}{ MCR } & Less than 5 months & 20 & 9 & $45 \%$ \\
\cline { 2 - 5 } & Greater than 5 months & - & - & - \\
\hline
\end{tabular}

\section{Discussion}

In this current study the comparison of the off-loading devices-total contact cast, ambulatory walking cast and modified MCR sandals was done with standard protocols and methods. The study has revealed the importance of offloading neuropathic diabetic ulcers and thereby halting the pathway to amputation.in this study patient treated with total contact cast have shown early epithelialisation of the wound and speedy healing, lesssepsis, more compliance than those treated with ambulatory walking cast or modified MCR chappels. Patients treated with ambulatory/removable cast walkers showed a healing rate less than that of total contact cast due to poor adherence of compliance by the patients. From all the devices TCC's have better outcomes in terms of ulcer followed by RCW and modified MCR sandals. The higher efficacy of TCC is because of the fact that it is irremovable and hence enforces compliances, both in terms of adherence to the device and follow-up. It is of importance that offloading has to be emphasized and is a corner stone for healing of neuropathic diabetic foot ulcers regardless of the type of device used, as long as it is appropriately used. It is necessary to emphasise that TCC are the best offloading devices and has to be considered. As first choice due to its higher efficacy in healing ulcers. The other device modified MCR sandals may be used when the ulcer is healed and pressure relief becomes important for prevention of recurrence or it may be used as a modality to prevent foot ulcers in diabetics in whom neuropathy has been identified.in this study most commonly developed adverse effect is skin irritation and infection. In total contact cast group it has to be accounted that the cast could have been tightly 
applied and hence rubbed against the skin of limb leading to ulceration and infection and participants are reviewed on a weekly basis unless unfeasible discomforts arise and this further influences the risk of infection.

\section{Conclusion}

In the present study on comparison of the efficacy of Total Contact Cost, Ambulatory Walking Cast and Modified MCR sandals in off-loading of diabetic neuropathic ulcers, based on our results, It is concluded that the Total Contact cast is superior to other modalities in healing the ulcers in terms of faster healing time, better healing rate, minimal adverse effects and good compliance.

\section{References}

[1]. Maciejewski ML, Reiber GE, Smith DG, Wallace C, Hayes S, Boyko EJ. Effectiveness of diabetic therapeutic footwear in preventing reulceration. Diabetes Care 2004; 27: 1774-1782.

[2]. CrossRef $\mid$ PubMed | Web of Science® Times Cited: 15

[3]. Reiber GE, Smith DG, Wallace C, et al. Effect of therapeutic footwear on foot reulceration in patients with diabetes: a randomized controlled trial. JAMA 2002; 287: 2552-2558.

[4]. CrossRef | PubMed | Web of Science ${ }^{\circledR}$ Times Cited: 55

[5]. Cavanagh PR, Boulton AJ, Sheehan P, Ulbrecht JS, Caputo GM, Armstrong DG. Therapeutic footwear in patients with diabetes. JAMA 2002; 288: 1231-1233, Author reply: 1232-3.

[6]. CrossRef | PubMed | Web of Science® Times Cited: 6

[7]. Chantelau E. Therapeutic footwear in patients with diabetes. JAMA 2002; 288: 1231-1232, Author reply: $1232-3$.

[8]. CrossRef $\mid$ PubMed $\mid$ Web of Science $®$ Times Cited: 6

[9]. Uccioli L, Faglia E, Monticone G, et al. Manufactured shoes in the prevention of diabetic foot ulcers. Diabetes Care 1995; 18: 1376-1378.

[10]. CrossRef | PubMed |CAS | Web of Science® Times Cited: 102

[11]. 6.Litzelman DK, Marriott DJ, Vinicor F. The role of footwear in the prevention of foot lesions in patients with NIDDM. Conventional wisdom or evidence-based practice? Diabetes Care 1997; 20: 156-162.

[12]. CrossRef | PubMed | CAS | Web of Science® Times Cited: 30

[13]. Dargis V, Pantelejeva O, Jonushaite A, Vileikyte L, Boulton AJ. Benefits of a multidisciplinary approach in the management of recurrent diabetic foot ulceration in Lithuania: a prospective study. Diabetes Care 1999; 22: 1428-1431.

[14]. CrossRef | PubMed |CAS | Web of Science® Times Cited: 42

[15]. Viswanathan V, Madhavan S, Gnanasundaram S, et al. Effectiveness of different types of footwear insoles for the diabetic neuropathic foot: a follow-up study. Diabetes Care 2004; 27: 474-477.

[16]. CrossRef | PubMed | Web of Science® Times Cited: 11

[17]. Striesow F. Special manufactured shoes for prevention of recurrent ulcer in diabetic foot syndrome. Med Klin (Munich) 1998; 93: $695-700$.

[18]. CrossRef | PubMed |CAS | Web of Science® Times Cited: 7

[19]. Mueller MJ, Sinacore DR, Hastings MK, Strube MJ, Johnson JE. Effect of Achilles tendon lengthening on neuropathic plantar ulcers. A randomized clinical trial. J Bone Joint Surg Am 2003; 85-A: 1436-1445.

[20]. PubMed | Web of Science® Times Cited: 67

[21]. Piaggesi A, Schipani E, Campi F, et al. Conservative surgical approach versus non-surgical management for diabetic neuropathic foot ulcers: a randomized trial. Diabet Med 1998; 15: 412-417.

[22]. Wiley Online Library | PubMed |CAS | Web of Science® Times Cited: 28

[23]. Armstrong DG, Lavery LA, Vazquez JR, et al. Clinical efficacy of the first metatarsophalangeal joint arthroplasty as a curative procedure for hallux interphalangeal joint wounds in patients with diabetes. Diabetes Care 2003; 26: 3284-3287.

[24]. CrossRef $\mid$ PubMed | Web of Science® Times Cited: 13

[25]. Armstrong DG, Rosales MA, Gashi A. Efficacy of fifth metatarsal head resection for treatment of chronic diabetic foot ulceration. J Am Podiatr Med Assoc 2005; 95: 353-356.

[26]. CrossRef $\mid$ PubMed $\mid$ Web of Science ${ }^{\circ}$ Times Cited: 5

[27]. Mueller MJ, Diamond JE, Sinacore DR, et al. Total contact casting in treatment of diabetic plantar ulcers. Controlled clinical trial. Diabetes Care 1989; 12: 384-388.

[28]. CrossRef | PubMed |CAS | Web of Science ${ }^{\circledR}$ Times Cited: 116

[29]. Caravaggi C, Faglia E, De GR, et al. Effectiveness and safety of a nonremovable fiberglass off-bearing cast versus a therapeutic shoe in the treatment of neuropathic foot ulcers: a randomized study. Diabetes Care 2000; 23: 1746-1751 